\title{
Geographic accessibility to public health facilities providing tuberculosis testing services at point-of-care in the upper east region, Ghana
}

Desmond Kuupiel ${ }^{1,7^{*}}$ (D) Kwame M. Adu ${ }^{2}$, Felix Apiribu ${ }^{1,3}$, Vitalis Bawontuo ${ }^{4,7}$, Duncan A. Adogboba ${ }^{5}$, Kwasi T. Ali ${ }^{6}$ and Tivani P. Mashamba-Thompson ${ }^{1}$

\begin{abstract}
Background: In Ghana, limited evidence exists about the geographical accessibility to health facilities providing tuberculosis (TB) diagnostic services to facilitate early diagnosis and treatment. Therefore, we aimed to assess the geographic accessibility to public health facilities providing TB testing services at point-of-care (POC) in the Upper East Region (UER), Ghana.

Methods: We assembled detailed spatial data on all 10 health facilities providing TB testing services at POC, and landscape features influencing journeys. These data were used in a geospatial model to estimate actual distance and travel time from the residential areas of the population to health facilities providing TB testing services. Maps displaying the distance values were produced using ArcGIS Desktop v10.4. Spatial distribution of the health facilities was done using spatial autocorrelation (Global Moran's Index) run in ArcMap 10.4.1. We also applied remote sensing through satellite imagery analysis to map out residential areas and identified locations for targeted improvement in the UER.

Results: Of the 13 districts in the UER, 4 (31\%) did not have any health facility providing TB testing services. In all, 10 public health facilities providing TB testing services at POC were available in the region representing an estimated population to health facility ratio of 125,000 people per facility. Majority (60\%) of the health facilities providing TB testing services in the region were in districts with a total population greater than 100,000 people. Majority (62\%) of the population resident in the region were located more than $10 \mathrm{~km}$ away from a health facility providing TB testing services. The mean distance \pm standard deviation to the nearest public health facility providing TB testing services in UER was $33.2 \mathrm{~km} \pm 13.5$. Whilst the mean travel time using a motorized tricycle speed of 20 $\mathrm{km} / \mathrm{h}$ to the nearest facility providing TB testing services in the UER was $99.6 \mathrm{~min} \pm 41.6$. The results of the satellite imagery analysis show that 51 additional health facilities providing TB testing services at POC are required to improve geographical accessibility. The results of the spatial autocorrelation analysis show that the spatial distribution of the health facilities was dispersed $(z$-score $=-2.3 ; p=0.02)$.

(Continued on next page)
\end{abstract}

\footnotetext{
* Correspondence: desmondkuupiel98@hotmail.com

${ }^{1}$ Department of Public Health Medicine, School of Nursing and Public Health, University of KwaZulu-Natal, Durban, South Africa

${ }^{7}$ Research for Sustainable Development Consult, Sunyani, Ghana

Full list of author information is available at the end of the article
}

(c) The Author(s). 2019 Open Access This article is distributed under the terms of the Creative Commons Attribution 4.0 International License (http://creativecommons.org/licenses/by/4.0/), which permits unrestricted use, distribution, and reproduction in any medium, provided you give appropriate credit to the original author(s) and the source, provide a link to the Creative Commons license, and indicate if changes were made. The Creative Commons Public Domain Dedication waiver (http://creativecommons.org/publicdomain/zero/1.0/) applies to the data made available in this article, unless otherwise stated. 
(Continued from previous page)

Conclusion: There is poor geographic accessibility to public health facilities providing TB testing services at POC in the UER of Ghana. Targeted improvement of rural PHC clinics in the UER to enable them provide TB testing services at $\mathrm{POC}$ is highly recommended.

Keywords: Geographic, Distribution, Accessibility, Health facilities, Tuberculosis, Point-of-care testing, Upper east region, Ghana

\section{Background}

Tuberculosis (TB) remains a global health threat and is one of the leading causes of death particularly human immunodeficiency virus (HIV) positive patients or among people living with acquired immunodeficiency syndrome [1, 2]. In 2017, the World Health Organization (WHO) global estimates show that, approximately 10 million people became ill with TB and more than 1.5 million died from the disease [1]. Over $94 \%$ of all $\mathrm{TB}$ deaths occurred in low- and middleincome countries (LMICs) including Ghana [1]. Ghana is classified as one of the countries with the highest double burden of TB and HIV, with a combined TB/HIV mortality rate of 18 per 100,000 populations translating to about 10,440 deaths per annum [3]. Early diagnosis and treatment of TB have been proven to be of greater benefits reducing morbidity and mortality as well as catastrophic cost related to TB treatment $[2,4]$.

The Government of Ghana (GOG) in her quest to reduce the impact of $\mathrm{TB}$ on the population over the years have made efforts to expand TB diagnostic services in the country through procurement of GeneXpert MTB/ RIF test for some rural health facilities and retooling of laboratories across the country's hospitals. Despites the continuous effort been made by the GOG and international organization, in 2017, out of the $14,550 \mathrm{~TB}$ case notifications received in Ghana, $6 \%$ of the patients were tested with rapid diagnostics at the time of diagnosis [5]. An average of 986 multi drug-resistant TB (MDR-TB) cases were reported in Ghana in the same period [5]. It also estimated that just about a quarter of MDR-TB cases are been detected yearly in Ghana, of which just close to half get cured $[6,7]$.

To reduce the burden of TB morbidity and mortality, more patients with TB need to be screened, diagnosed, and treated or prevented from developing TB illness in the first place $[2,3]$. Prevention of TB cases is particularly critical in rural and resource-limited settings, where access to point-of-care (POC) testing and diagnosis of patients with tuberculosis can be very much challenging. Most rural primary health care (PHC) facilities commonly lack laboratory infrastructure and the required human resource capacity to diagnose TB. One of the most effective ways to improve early diagnosis and treatment of patients with $\mathrm{TB}$ is to empower rural and resource-limited PHC clinics to be able to carry out POC testing for suspected TB patients. Our earlier survey of PHC clinics in the Upper East Region (UER), Ghana aimed at evaluating the accessibility of POC diagnostic services demonstrated poor availability of TB testing [8]. In view of this, we aimed to assess the geographic accessibility to public health facilities providing TB testing services at POC in the UER, Ghana. To the best of our knowledge, no such study has been conducted before in the region and, we anticipate that the results will be useful for planning to reduce the catastrophic cost associated with TB diagnosis and treatment as well as towards achieving the End TB Strategy by 2035 [9].

\section{Methods \\ Overview}

Figure 1 shows schematically the various data and modelling components used to achieve the objective of this study. The methodological aim of this study was to model geographical access of patients to health facilities providing TB testing services in the UER, Ghana. The region with 13 administrative districts is in the north-eastern corner of Ghana, bordered by Burkina Faso to the north, Togo and Upper West Region to the east, and Northern Region to the south. The region had 1,244,983 people in 2018 and is considered largely (79\%) rural and scattered in dispersed settlements [10]. The main source of income for most of the population is farming.

The study spatially referenced or obtained locational data of all health facilities providing TB testing services via a prior survey aimed to assess the accessibility of POC diagnostic tests in the region [8], and the use of global positioning system (GPS). Thereafter, we applied the world geodetic system (WGS) Zone 30 North coordinate system to all spatial data in order to allow for results of spatial processes in a preferred unit of 'meters'. Topographic data included roads, rivers and the digital elevation model (DEM). A previous survey in the region preceding this present study showed that 


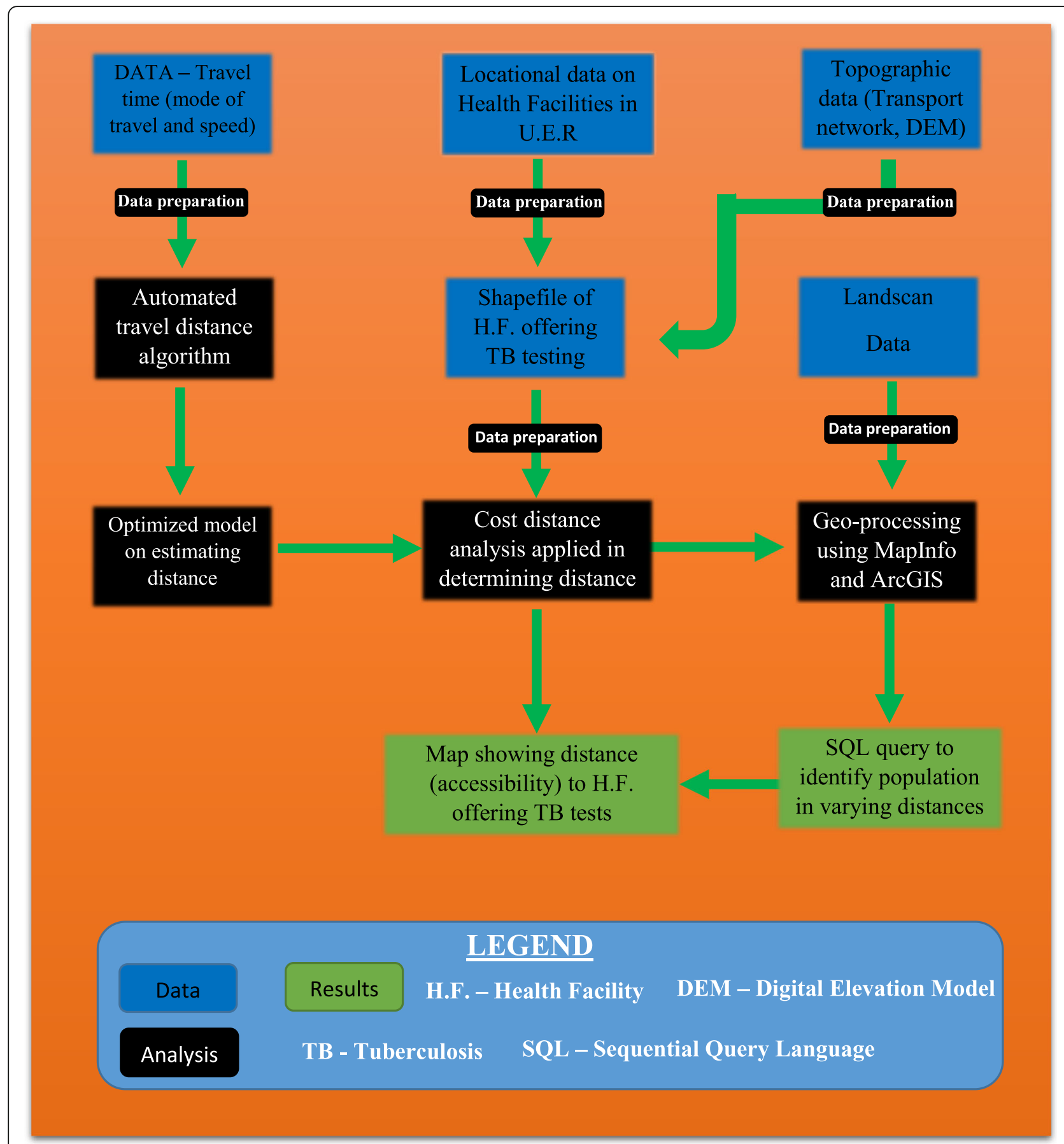

Fig. 1 Process flow diagram for the procedures undertaken to arrive at the results

motorized tricycle popularly known as "Moto king" was the most utilized public transport option [8]. We estimated travel time via road and paths/tracks based on the "Moto King" transport system. This involved recalibrating travel time per pixel ( $10 \mathrm{~m}$ by $10 \mathrm{~m}$ grid) for both roads and paths. This ultimately helped to estimate travel time from settlement areas of the population to health facilities offering $\mathrm{TB}$ testing for all the districts in the region.

\section{Geo-database of TB testing health facilities}

Spatial and attribute (A-spatial) data on TB testing health facilities was collected and prepared by assigning one coordinate system to all the data to allow for 
synchronization. We then loaded the data in google earth to determine and confirm their location via landmarks and other reconciliatory features. The data was then imported into ArcGIS in the point shapefile format. The spatial data obtained primarily covered the 'what' and the 'where' that is, the clinic or hospital name and location (coordinates). Besides the name, other attribute data included the district where the facility is located (district name), the type of health clinic (health center, hospital, and others), whether they provided TB testing services and the commonly used public transport option. A crosssection survey prior to this study helped eliminate public health facilities that do not provide TB testing services from the analysis [8]. These were filtered out using the select by attribute function and eventually clipped.

\section{Topographic data}

This data covered digitised and georeferenced road networks and paths well as features like rivers and lakes. The DEM of the region was also obtained to help identify natural barriers such hills and valleys as well as undulating land that would inform the decision on estimating travel time. All data was obtained from Adu Manu Kwame (AMK) Consult and juxtaposed with data obtained from the University of Ghana Remote Sensing and Geographic Information Systems laboratory to validate accuracy. The DEM was then reclassified into highlands (more than 200 $\mathrm{m}$ high) and flatlands (between 119 and $200 \mathrm{~m}$ high). This was determined by the DEM data which showed that the highest point in the region was about $470 \mathrm{~m}$ whiles the lowest point identified as $119 \mathrm{~m}$.

\section{Model for estimating travel time}

This was accomplished using a sequence of algorithms with the final output incorporating cost distance tool in ArcGIS 10.4. Cost distance calculates the shortest time to a source based on a cost dataset. To realize this, a cost surface algorithm was designed with these parameters: a grid cell of size $10 \mathrm{~m}$ was assigned to the spatial features and values were then assigned to the predetermined grids. Roads were assigned low values because traveling on roads is faster than travel via paths and travel over impediments such as water bodies and rocky areas takes a much longer time and hence assigned higher values. Since cost distance requires the cost surface dataset and the source, the raster dataset served as the cost surface dataset and health facilities providing TB testing served as the source for calculating the cost distance. The output is a map showing shortest travel time (cell by cell) from any point in the map to a health facility providing TB testing services in the region. Algorithms which allowed for carrying out conversion of data from vector to raster, map algebra (cost surface models) and cost distance was developed using Python 2.7. Designing the algorithm helped to avoid repeating the various processes for the varying districts via the ArcMap toolbox. Based on prior information on the most commonly used public transportation option in the UER, the travel speed of a motorised tricycle was pecked at $20 \mathrm{~km} / \mathrm{h}$. This served as a guide for determining travel time in the region. A detailed description of the model is presented in Additional file 1.

\section{Determining distance for population}

The Oakwood Ridge National Laboratory Landscan data set serves as a standardized and globally accepted population distribution data [11]. This data was mapped in MapInfo and an SQL query was employed in clipping out the population distribution within all the available travelling distances from health facilities offering TB testing.

\section{Outcome measures}

The primary outcome of this study was geographical accessibility to health facilities offering TB testing in UER, Ghana. Geographical accessibility was measured as: 0$10 \mathrm{~km}=$ good geographical access; and $>10 \mathrm{~km}=$ poor geographical access. Considering $\leq 10 \mathrm{~km}$ as good geographical accessibility be arbitrary. However, evidence shows that access to healthcare beyond $10 \mathrm{~km}$ is associated with higher risks of adverse outcomes [12]. Also, categorising geographical accessibility using travel time would have been useful but, travel time depends on the mode of transportation option and the route hence our choice to base our categorisation of geographical accessibility on distance. The secondary outcome of this study was to identify locations for targeted improvement of TB testing services in the UER utilizing geographical models and the application of remote sensing through satellite imagery analysis. Remote sensing also known as earth observation, refers to acquiring information about objects located on the earth's surface without being in direct contact with the said object. The application of remote sensing through satellite imagery afforded us the opportunity to observe locations that had settlements and help us properly cite proposed health clinics without necessarily having to visit the region.

\section{Statistical analysis}

Spatial autocorrelation tool or Global Moran's I [13] was run in ArcMap 10.4.1 to determine the spatial distribution of the health facilities providing TB diagnostic services in the UER. The Global Moran's I statistic was run with the region as the input feature class and the count of health facilities providing TB testing services in each district as the input field to determine the spatial distribution of the health facilities. Z-scores and $p$-values were generated and reported. Mean and standard deviation (SD) for distance and travel time were also reported. 


\section{Results}

\section{Distribution of the health facilities providing TB testing services in UER}

In all, 10 public health facilities providing TB testing services at POC existed in the region This represented an estimated population to health facility ratio of 125,000 people per facility in the UER. Of the 10 facilities, 9 (90\%) were owned by the Ghana Health Services, and the remaining one $(10 \%)$ owned by the Presbyterian church, a member of the Christian Health Association of Ghana. Majority (60\%) of the health facilities providing TB testing services in the region were in districts with a total population greater than 100,000 people. Two (20\%) of the 10 facilities were in the Bawku West district, and one (10\%) each in the remaining 8 (69\%) districts and municipalities in the region. Four districts (Builsa South, Nabdam, Pusiga, and Binduri) did not have any health facility providing TB testing services located in the districts. Table 1 shows the population distribution per public health facility providing TB testing services in the UER based on the sum of health facilities providing the service in each district.

\section{Spatial distribution of health facilities offering TB testing services in upper east region}

The spatial autocorrelation analysis was carried out to determine how spatially distributed the health facilities providing TB testing services are, in the UER. The result shows that the health facilities were dispersed ( $\mathrm{z}$-score $=$ $-2.3 ; p=0.02$ ), as illustrated in Fig. 2 .

\section{Geographic accessibility to TB testing services in the upper east region}

Figure 3 shows 13 modelled surfaces estimating distances values from the population to existing health facilities offering TB testing services in the UER. The maps provide visual prominent indications of the degree of variations in levels of geographical accessibility in relation to distance in the region. Of the 13 districts, 4 (31\%) districts namely; Nabdam, Binduri, Builsa South, and Pusiga did not have any facility offering TB test. Suspected TB patients residing in Pusiga district would have to travel to the nearest health facility (Bawku Presbyterian hospital) which is situated in neighboring Bawku municipal for TB testing services. Suspected TB patients living in Binduri district however are bounded by four health facilities providing TB testing services: to the West by Zebilla Hospital (Bawku West), to the South-West by Binaba Health Centre (Bawku West), to the South-East by Garu Health Centre (Garu-Tempane), and to the North-East by Bawku Presbyterian Hospital (Bawku municipal). Nabdam district is also bordered by four districts (Bolgatanga Municipal, Bawku West, Talensi and Bongo) which have health facilities providing TB testing services and suspected TB patients referred from $\mathrm{PHC}$ clinics for testing would have to travel to the nearest TB facility. Patients resident in the Northern part of Talensi would be better served (by a short distance) if they opt to visit Zebilla hospital in the Bawku West district as the estimated distance according to the cost distance algorithm would be generally between 20 to $25 \mathrm{~km}$. Patients residing in the central and southern part of Nabdam would have the most difficulty in reaching any health facility providing $\mathrm{TB}$ testing services partly due to lack of good roads to allow for faster travel and hence reduced travel distance. The spatial analysis reveals that all TB suspected patients' resident in the central and southern part of Nabdam district are at least $30 \mathrm{~km}$ away from the nearest health facility providing TB

Table 1 Distribution of health facilities providing TB testing services per population in the UER

\begin{tabular}{llll}
\hline District & Name of facility $(N=10)$ & Population $(N=1,244,983)$ & Population/facility \\
\hline Builsa North & Sandema hospital & 67,190 & 67,190 \\
Kassena Nankana West & Paga health center & 84,585 & 84,585 \\
Kassena Nankana Municipal & War Memorial hospital & 130,593 & 130,593 \\
Bolgatanga Municipal & Bolgatanga Regional hospital & 156,678 & 156,678 \\
Talensi & Tongo hospital & 97,010 & 97,010 \\
Bongo & Bongo hospital & 100,741 & 100,741 \\
Bawku West & Zeibilla hospital & 105,970 & 105,980 \\
& Binaba health center & 5970 & 5960 \\
Garu Tempane & Garu health center & 154,214 & 154,214 \\
Bawku Municipal & Bawku Presbyterian hospital & 116,912 & 116,912 \\
Builsa South & Not available & 43,534 & - \\
Nabdam & Not available & 39,798 & - \\
Binduri & Not available & 73,382 & - \\
Pusiga & Not available & 68,406 & - \\
\hline
\end{tabular}




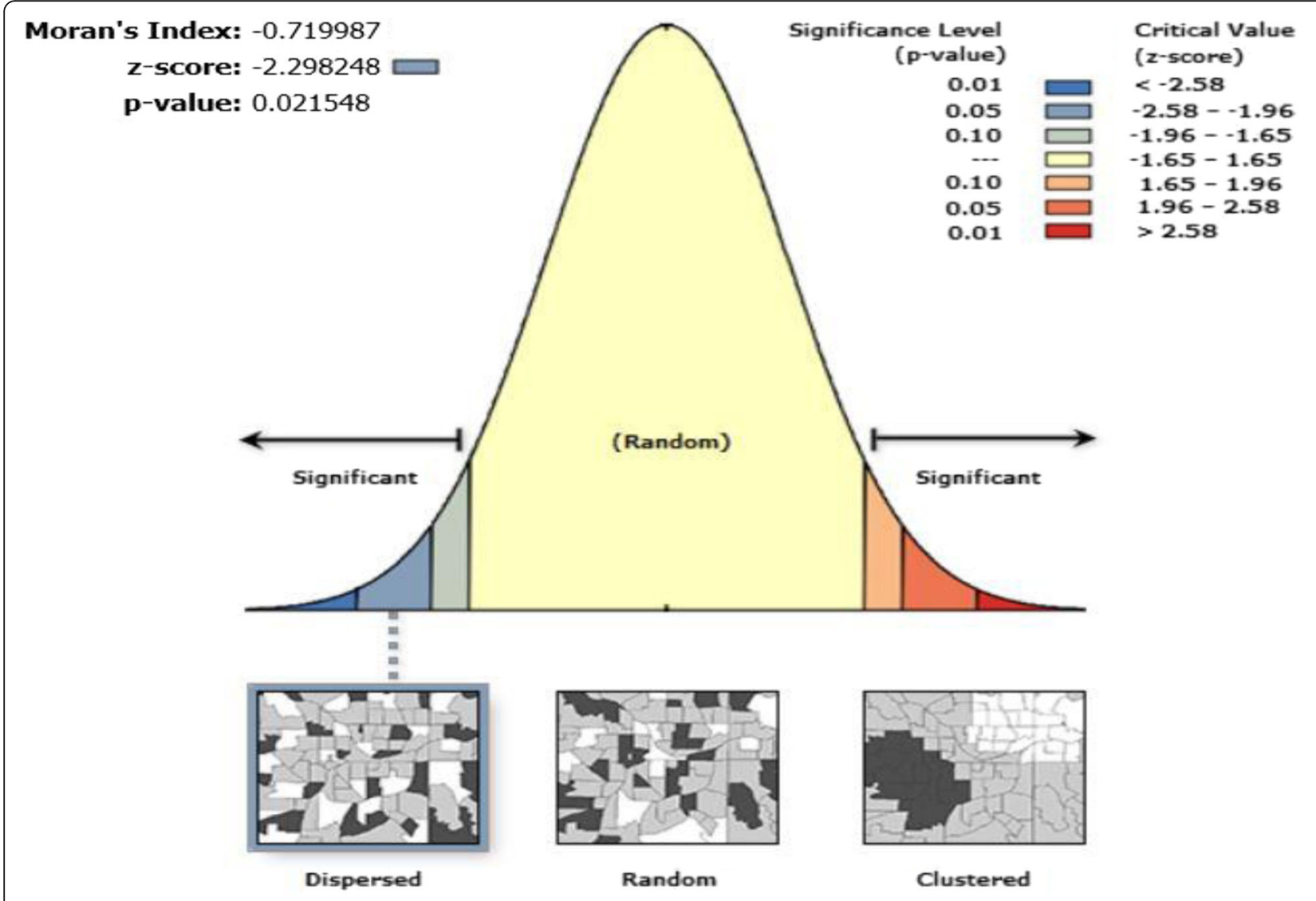

Given the $z$-score of -2.29824811078 , there is a less than $5 \%$ likelihood that this dispersed pattern could be the result of random chance.

Fig. 2 Spatial distribution of health facilities offering TB testing in the UER

testing. The closest referral health facility offering $\mathrm{TB}$ testing services to people living in the Builsa South is Sandema hospital which is averagely $30 \mathrm{~km}$ from all residential areas in the district.

Table 2 shows the distance and travel time distribution per population in the UER. Cumulatively, the spatial analysis shows that just about $38 \%$ of the population residents in the UER have good geographic access (less than $10 \mathrm{~km}$ ) to a health facility providing TB testing services. Majority (62\%) of suspect TB patients referred from PHC clinics for $\mathrm{TB}$ testing in the region however will have to travel more than $10 \mathrm{~km}$ to access a facility for the service. The mean distance \pm SD to the nearest public health facility providing TB testing services in UER was $33.2 \mathrm{~km} \pm 13.5$. Whilst the mean travel time \pm SD using a motorized tricycle speed of $20 \mathrm{~km} / \mathrm{h}$ to the nearest facility providing TB testing services in the UER was $99.6 \mathrm{~min} \pm 41.6$. The longest mean distance and travel time was recorded in the Builsa South district that is, $53.8 \mathrm{~km} \pm 13.1$ and $161.4 \mathrm{~min} \pm 40.2$ respectively. Bawku Municipal recorded the shortest distance and travel time to the nearest facility providing TB testing services in the region that is, $21.1 \mathrm{~km} \pm 8.3$ and $63.3 \mathrm{~min} \pm 25.7$ respectively, as illustrated in Table 3.

\section{Proposed sites for targeted improvement of TB POC testing services in the UER}

To improve geographic accessibility to TB testing services in the region, this study proposed that there should be at least one health facility providing TB testing services located not more than $10 \mathrm{~km}$ from where people live. Base on this, the study employed geographical models to estimate 51 additional healthcare facilities for targeted improvement to meet the unmet TB diagnostic needs of the people resident in the UER. Figure 4 shows a map of the proposed locations of health facilities for targeted improvement to increase geographic access to TB diagnostic service in the UER.

To ensure that all the 51 proposed health facilities would not be in an uninhabited area (example, in the forest), remote sensing (satellite imagery) was first done to 


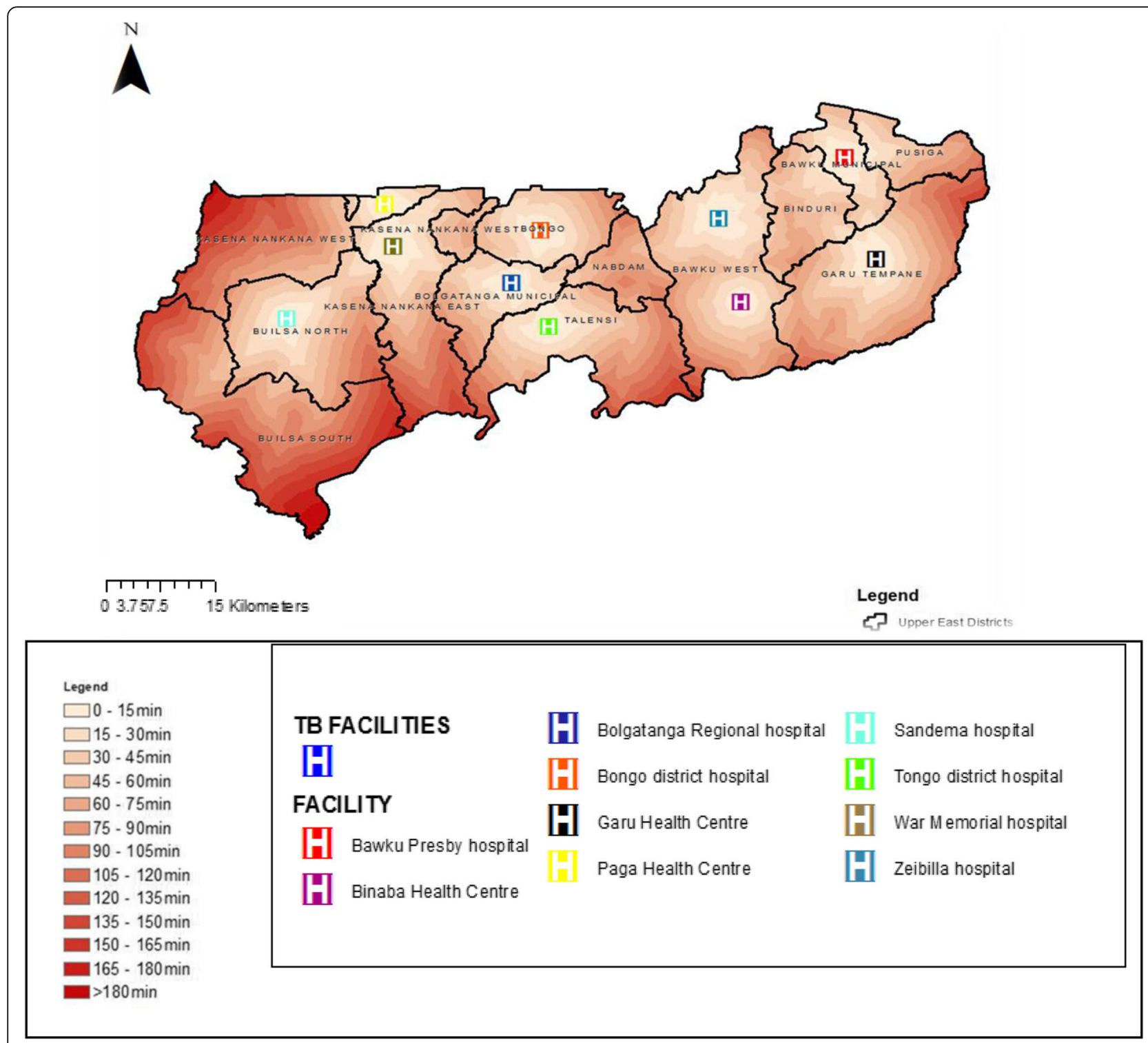

Fig. 3 Map showing accessibility to health facilities offering tuberculosis diagnostic services in the Upper East Region

map out settlement zones and the areas within $10 \mathrm{~km}$ range of the already existing public health facilities providing TB testing services in the UER. An application of the satellite imagery analysis helped to reduce the initially identified 97 health facilities to 51 for targeted improvement to ensure geographical accessibility (less than 10 $\mathrm{km})$ to TB testing services for all residents in the region. The remote sensing classification method of unsupervised classification was used to determine settlement and nonsettlement areas (forests). In the supervised classification method, pixels are placed into clusters based on their digital numbers. For example, pixels that capture forest areas are similar and as such, the software classifies all such pixels into a cluster of forest area. The resulting classes were converted from raster to vector data. Using this, a clip function was performed to remove all proposed health facilities that fell in forest areas. Due reduction was achieved after deleting all proposed health facilities falling outside settlements leaving those critical to meeting the unmet diagnostic needs of populations reciting in poor geographical access areas. Figure 5 shows a map of residential zones and areas within $10 \mathrm{~km}$ coverage by the existing public health facilities providing TB testing services in the UER.

\section{Discussion}

Geographic access to care is difficult to measure hence the international community most often defined targets based on facility provision per capita [14]. In this study, we assembled unique spatial data on health facilities providing $\mathrm{TB}$ 
Table 2 Distribution of distance and travel time per population in the UER

\begin{tabular}{llll}
\hline Distance $(\mathrm{Km})$ & Travel time (Minutes) & Population $(\mathrm{N}=1,244,983)$ & Share of population $(\%)$ \\
\hline 0 to 5 & $0-15$ & 286,346 & $23 \%$ \\
5 to 10 & $15-30$ & 186,747 & $15 \%$ \\
10 to 15 & $30-45$ & 174,298 & $14 \%$ \\
15 to 20 & $45-60$ & 161,848 & $13 \%$ \\
20 to 25 & $60-75$ & 136,947 & $11 \%$ \\
25 to 30 & $75-90$ & 99,599 & $8 \%$ \\
30 to 35 & $90-105$ & 74,699 & $3 \%$ \\
35 to 40 & $105-120$ & 37,349 & $2 \%$ \\
40 to 45 & $120-135$ & 24,900 & $2 \%$ \\
45 to 50 & $135-150$ & 24,900 & $1 \%$ \\
50 to 55 & $150-165$ & 12,450 & $1 \%$ \\
50 to 60 & $165-180$ & 12,450 & $1 \%$ \\
\end{tabular}

testing services, population, and topographic landscape, as well as supporting survey to assess realistic levels of geographic accessibility to public health facilities providing TB testing services at POC in the UER. This study results show majority $(62 \%)$ of the population travel beyond $10 \mathrm{~km}$ to access TB diagnostic testing in the region. It also revealed that TB diagnostic service was available in only ten health facilities in the UER which translates to approximately 125,000 people per facility considering the region's current total population of $1,244,983$. This study further revealed that four districts did not have any health facility providing TB diagnostic services. However, the spatial distribution of the public health facilities providing TB testing services were revealed to be dispersed in the region.
Although geographic accessibility is not the only determinant of access to health care, where service provision is sparse, and the population is predominantly rural, it plays a critical role for healthcare outcomes [14]. Poor geographic accessibility to public health facilities providing TB testing services at POC revealed by this study implies patients in referred from $\mathrm{PHC}$ clinics in rural areas have to walk for hours or pay exorbitant transport fares to access TB diagnostic services [15]. Patients often have the tendency to limit or utilize essential health care services closer to them [16]. Majority of rural populations in low and middle income countries are farmers [17]. Therefore, a clients may fail to go for a test or go back for test results when asked to come back the following day

Table 3 Summary of mean (standard deviation) distance and travelling time to the nearest health facility providing TB testing services in each district

\begin{tabular}{lllll}
\hline District & Mean/average distance $(\mathrm{km})$ & Standard deviation & Mean /average travelling time $(\mathrm{min})$ & Standard deviation \\
\hline Builsa North & 32.5 & 17.9 & 97.5 & 55.7 \\
Kassena Nankana West & 39.8 & 18.7 & 119.4 & 57.4 \\
Kassena Nankana Municipal & 33.9 & 18.5 & 101.7 & 57.2 \\
Bolgatanga Municipal & 25.7 & 12.9 & 77.1 & 40.4 \\
Talensi & 41.6 & 16.1 & 124.8 & 48.2 \\
Bongo & 28.1 & 13.5 & 84.3 & 41.6 \\
Bawku West & 33.2 & 16 & 99.6 & 48.8 \\
Garu-Tempane & 37.6 & 14.1 & 112.8 & 43.4 \\
Bawku Municipal & 21.1 & 8.3 & 63.3 & 25.7 \\
Builsa South & 53.8 & 13.1 & 161.4 & 40.2 \\
Nabdam & 32.9 & 9.9 & 98.7 & 31.1 \\
Binduri & 24.3 & 6.8 & 72.9 & 20.7 \\
Pusiga & 27.2 & 10 & 81.6 & 30.7
\end{tabular}




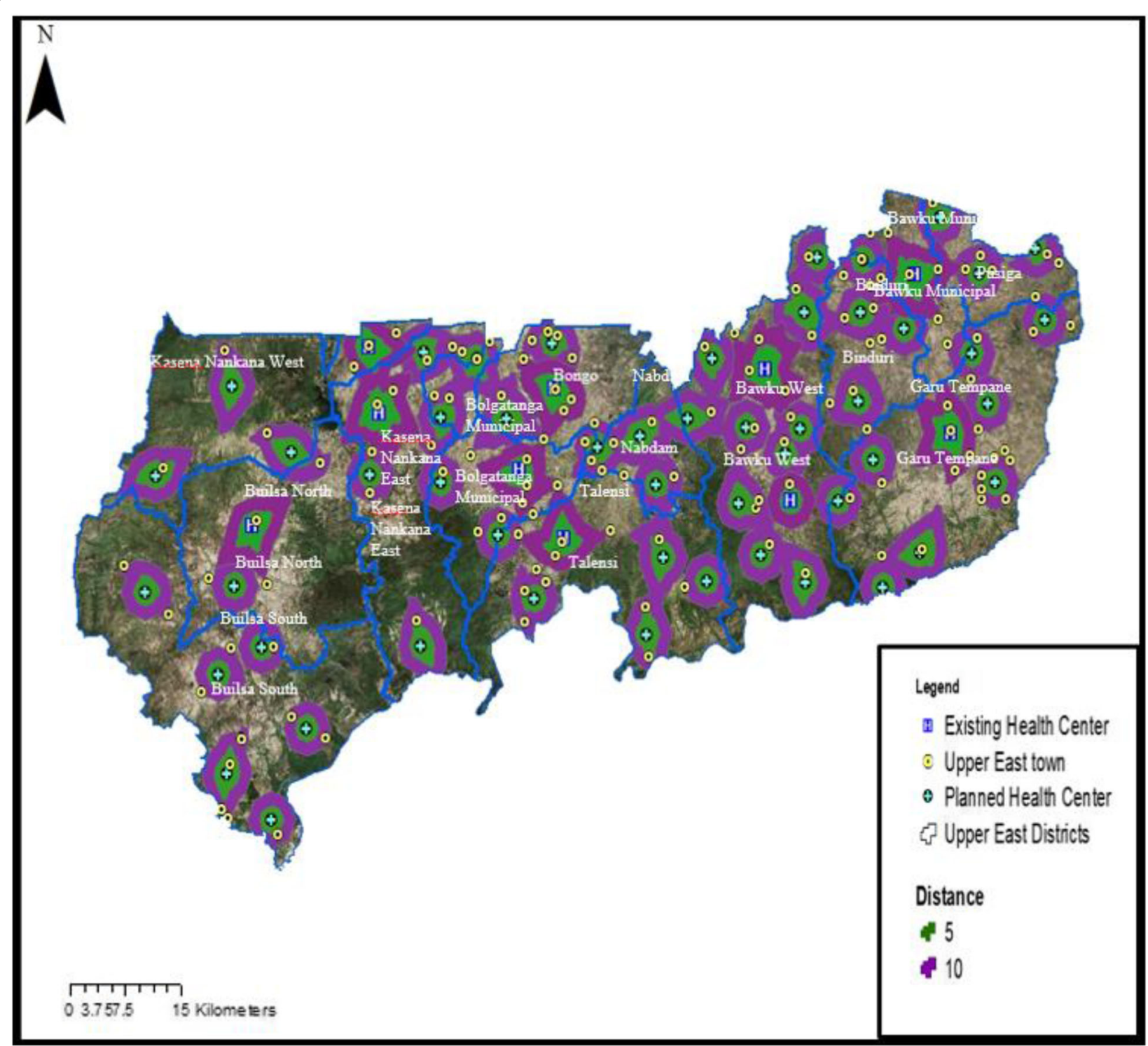

Fig. 4 Map showing proposed locations of health facilities for targeted improvement to increase geographic access to TB diagnostic service in the UER

or week especially at certain times of the season [18]. Dangisso et al. (2015) study in Ethiopia demonstrated TB case notification rates were higher in areas where people had good access to diagnostic and treatment facilities [15]. Finnie et al. (2011) aimed to identify factors causing delayed diagnosis and treatment for tuberculosis in high TB/HIV burden African countries also demonstrated travel time associated with delays in patients returning for care $[19,20]$. Although the spatial distribution of the health facilities providing TB testing services were revealed to be dispersed in the UER, this is deemed desirable to maximize accessibility to TB testing services.

In this study we employed the geospatial methodology to assess the geographical distribution of health facilities providing TB testing services at POC and their proximity to the population. Spatial accessibility measures have been shown to be important policy tool for managing health care provision and reducing health disparities [21, 22]. We used census data from the Ghana statistical service whiles also taking into consideration other geographic data and incorporated remote sensing of aerial data to accurately distribute population within all political boundaries. The application of remote sensing through satellite imagery afforded us the opportunity to observe locations that had settlements as well as enabled us to properly cite proposed health clinics without necessarily having to visit the region. Each population distribution data is unique because it takes into account, 


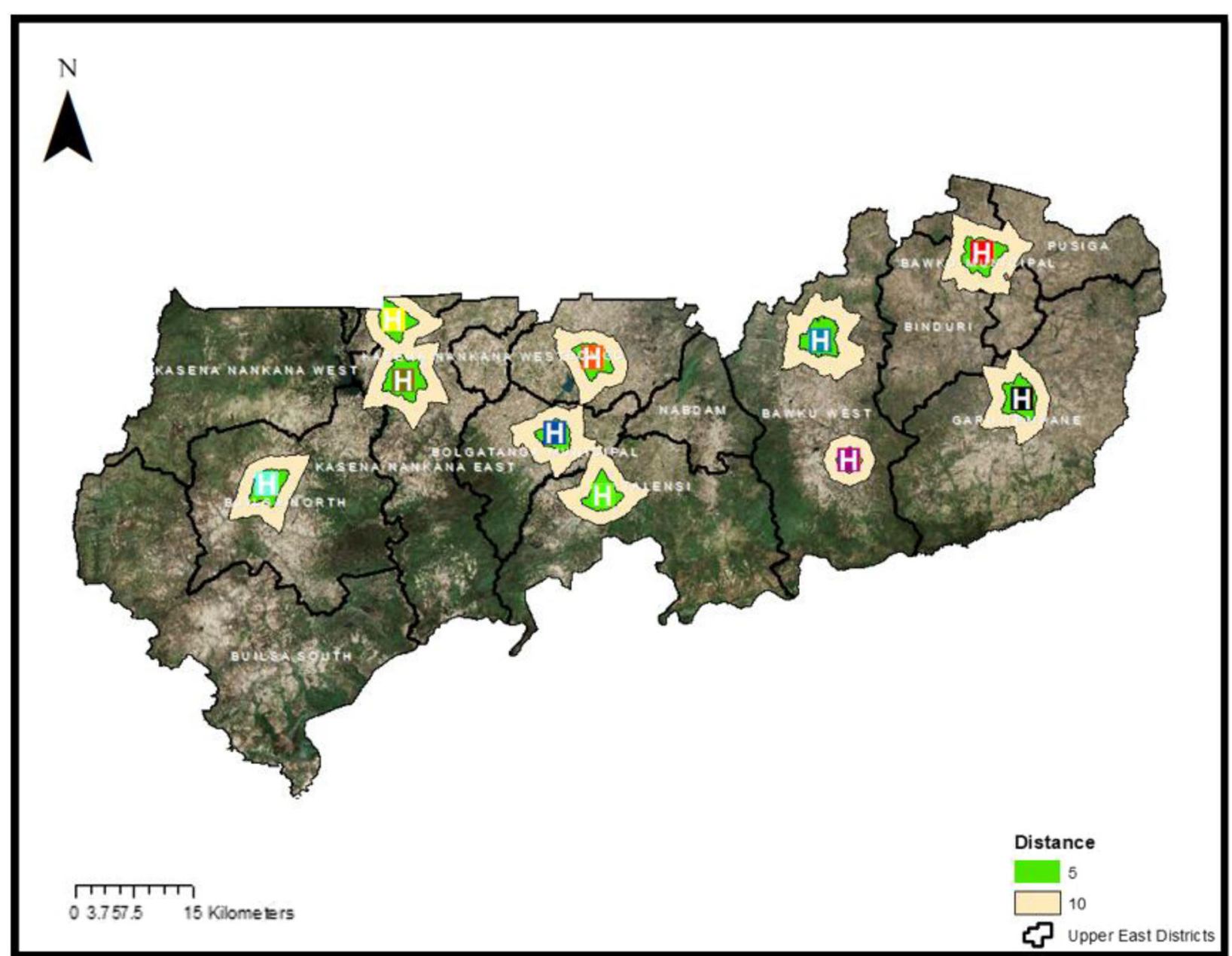

Fig. 5 Map showing residential zones and areas within $10 \mathrm{~km}$ coverage by existing public health facilities providing TB testing services in the UER

the prevailing conditions and spatial nature of each and every region [23]. This study methodology enables us to identify poor geographic access to public health facilities for TB testing services in the UER. Health sector budgetary allocation of countries like Ghana is poor and most often supported by development partners, International organizations, and donors with many competing interests. Therefore, the spatial methodology adopted by this study has strength of informing policy makers to plan and implement $\mathrm{TB}$ diagnostic testing services in poor geographic access areas.

Despite the above-mentioned strengths of the study, the following limitations should be noted. Although, we assembled a comprehensive set of data describing the landscape, it is possible we may not have captured all local details such as the prevalence or incidence rate of $\mathrm{TB}$ in the UER. We therefore recommend future studies to focus on mapping and determining how many TB cases fall within 'high' versus 'low' accessible areas in the region. Also, using an assumed motorized tricycle speed of $20 \mathrm{~km}$ /hour to calibrate travel time may always not be applicable since other transportation options such as walking, use of a motorbike, bicycle or a car may be utilized by some patients to the health facilities. In addition, traveling time may be affected by seasonal changes, traffic, and other essential factors. Nonetheless, this study provided very useful information to help planning and improve geographical access to TB POC testing particularly for rural populations.

Efforts to reduce TB morbidity, mortality, and catastrophic cost associated with treatment by improving the quality and availability of diagnostic services and treatment in selected health facilities will have limited impact where long distances, poor infrastructure at the PHC level, lack of good roads and transport systems means patients referred from $\mathrm{PHC}$ clinics may be unable to access services timely. To improve TB care the WHO recommends $\mathrm{TB}$ testing alongside other POC test in resource-limited settings in its maiden list of essential diagnostics [24]. Geographic accessibility is a key aspect 
of ensuring better health care and treatment for people and clearly, in the case of the UER as demonstrated by this study, a higher proportion of the populace are located at a significantly longer distance away from public health facilities providing TB testing services. Hence, this study proposed an improvement of at least 51 PHC clinics in the UER to enable them provide TB testing services. Improving road networks and making available faster and safer transport systems in rural areas in the region would also greatly improve travel time as well.

\section{Conclusion}

The study findings show poor geographic accessibility to public health facilities providing TB testing services at POC in UER, Ghana. The findings of this study have provided evidence-based information to help with planning and improving $\mathrm{TB}$ testing services targeting first rural PHC clinics located in poor geographic access areas in the region. Travelling long distances to access a health facility for TB testing outside one's location can be a limiting factor for most suspected TB patients and hence, could affect the successes chalked so far toward the end TB strategy in the region. Long distances also may result in late diagnosis and treated as well as worsen the catastrophic cost currently associated with TB treatment in Ghana. To reduce the impact of TB infection, diagnosis, treatment, and related catastrophic cost related in Ghana and other LMICs, the measurement of geographical accessibility is very relevant to provide evidence-based strategies to improve TB care. We will like to recommend a replication of this study in high prevalence regions in Ghana and other TB high prevalence countries. We also recommend $\mathrm{TB}$ active case finding in low prevalence regions especially among high risk populations to facilitate achievement of the end TB strategy by 2035 .

\section{Additional file}

Additional file 1: Detailed description of model for estimating travel time (DOCX $15 \mathrm{~kb})$

\section{Abbreviations}

DEM: Digital elevation model; GOG: Government of Ghana; LMICs: low- and middle-income countries; PHC: Primary Health Care; POC: Point-of-Care; RHD: Regional Health Directorate; SDGs: Sustainable Development Goals; TB: Tuberculosis; UER: Upper East Region; WHO: World Health Organization

\section{Authors' contributions}

DK conceptualized the study and developed the analytical strategy. DK collected the data, processed the data, performed analysis and interpreted the results, and wrote the first draft of the study. KMA contributed to the analysis and interpretation of the results. DAA assisted with data collection. FA, and KTA critically review the first draft manuscript. TPM-T and VB contributed to the analytical strategy, interpretation of the results, and did critical revisions. DK wrote the final draft and it was approved by all authors.

\section{Authors' information}

Dr. Desmond Kuupiel: Postdoctoral Researcher in the Discipline of Public Health Medicine, School of Nursing and Public Health, University of KwazuluNatal, South Africa.

Kwame M. Adu: Geographical Information Analyst and the director of AMK Consultancy, Accra, Ghana.

Felix Apiribu: A lecturer with the Kwame Nkrumah University of Science and Technology, Kumasi, Ghana, and a PhD Nursing student, School of Nursing and Public Health, University of Kwazulu-Natal, South Africa.

Dr. Vitalis Bawontuo: He is the Dean of the Faculty of Health and Allied Sciences, Catholic University College of Ghana, Fiapre, Sunyani.

Duncan A. Adogboba: Regional Research Officer, Regional Health Directorate, Ghana Health Service, Upper East Region, Ghana.

Dr. Kwasi T. Ali: Director of Health Services, Goaso Diocese, Brong Ahafo Region, Ghana.

Dr. Tivani P. Mashamba-Thompson: Academic Leader Research for the School of Nursing and Public Health, University of KwaZulu-Natal, South Africa.

\section{Funding}

This study was funded by the University of KwaZulu-Natal, College of Health Sciences Research Scholarship.

\section{Availability of data and materials}

Data from this study cannot be shared publicly because it contains sensitive, identifying patient information. All interested researchers/readers/persons who meet the criteria for access to confidential data can access the data set via Dr. Tivani P. Mashamba-Thompson, the project supervisor and the Academic Leader (Research) for the School of Nursing and Public Health via this email address: Mashamba-Thompson@ukzn.ac.za. Data access may also be requested from the University of KwaZulu-Natal Biomedical Research Ethics Committee (BREC) from the following contacts: The Chairperson BIOMEDICAL RESEARCH ETHICS ADMINISTRATION Research Office, Westville Campus, Govan Mbeki Building University of KwaZulu-Natal P/Bag X54001, Durban, 4000 KwaZulu-Natal, South Africa Tel.: + 27 312,604,769 Fax: + 27 312,604,609 Email: BREC@ukzn.ac.za.

\section{Ethics approval and consent to participate}

This study was approved by the Navrongo Health Research Centre Institutional Review Board/Ghana Health Service (approval number: NHRCIRB291) and the University of KwaZulu-Natal Biomedical Research Ethics Committee (approval number: BE565/17). Permission was obtained from the Upper East Regional Health Directorate prior to conducting the study. All study participants signed an informed consent prior to participating in this study.

\section{Consent for publication}

Not applicable.

\section{Competing interests}

The authors declare that they have no competing interests.

\section{Author details}

${ }^{1}$ Department of Public Health Medicine, School of Nursing and Public Health, University of KwaZulu-Natal, Durban, South Africa. ${ }^{2}$ Department of geography, University of Ghana, Legon, Ghana. ${ }^{3}$ Department of Nursing, Kwame Nkrumah University of Science and Technology, Kumasi, Ghana. ${ }^{4}$ Faculty of Health and Allied Sciences, Catholic University College of Ghana, Fiapre, Sunyani, Ghana. ${ }^{5}$ Regional Health Directorate, Ghana Health Service, Upper East Region, Bolgatanga, Ghana. ${ }^{6}$ Catholic Health Services, Goaso Diocese, Goaso, Brong Ahafo Region, Ghana. ${ }^{7}$ Research for Sustainable Development Consult, Sunyani, Ghana.

Received: 19 November 2018 Accepted: 27 May 2019

Published online: 10 June 2019

\section{References}

1. World Health Organization. Global tuberculosis report 2017. Geneva: The World Health Organization; 2017. https://www.who.int/tb/publications/ global_report/gtbr2017_main_text.pdf. [Accessed 7 June 2019].

2. Gupta-Wright A, Corbett EL, van Oosterhout JJ, Wilson D, Grint D, Alufandika-Moyo M, et al. Rapid urine-based screening for tuberculosis in 
HIV-positive patients admitted to hospital in Africa (STAMP): a pragmatic, multicentre, parallel-group, double-blind, randomised controlled trial. Lancet. 2018;392(10144):292-301.

3. Dodd PJ, Yuen CM, Becerra MC, Revill P, Jenkins HE, Seddon JA. Potential effect of household contact management on childhood tuberculosis: a mathematical modelling study. Lancet Glob Health. 2018;6:e1329-e1338.

4. Bjerrum S, Kenu E, Lartey M, Newman MJ, Addo KK, Andersen AB, et al. Diagnostic accuracy of the rapid urine lipoarabinomannan test for pulmonary tuberculosis among HIV-infected adults in Ghana-findings from the DETECT HIV-TB study. BMC Infect Dis. 2015;15(1):407.

5. World Health Organization. Ghana Tuberculosis Profile 2017. Available from: https://extranet.who.int/sree/Reports?op=Replet\&name=/WHO_HQ Reports/G2/PROD/EXT/TBCountryProfile\&ISO2=GH\&outtype=pdf. [cited 2018 3/10/2018]

6. World Health Organization. Global tuberculosis report 2016. 2016.

7. Asandem DA, Asante-Poku A, Asare P, Aboagye SY, Stephen OW, Danso E, et al. OMNlgene SPUTUM: a good transport and decontaminating reagent for tuberculosis testing. Int J Mycobacteriol. 2018;7(3):222-7.

8. Kuupiel D, Tlou B, Bawontuo V, Mashamba-Thompson TP. Accessibility of pregnancy-related point-of-care diagnostic tests for maternal healthcare in rural primary healthcare facilities in northern Ghana: a cross-sectional survey. Heliyon. 2019;5(2):e01236.

9. World Health Organization. Implementing the end TB strategy: the essentials. Geneva: The World Health Organization; 2015. https://www.who. int/tb/publications/2015/end_tb_essential.pdf. [Accessed 7 June 2019].

10. Ghana Statistical Service. 2010 Population \& Housing Census: Summary Report of Final Results Accra: Ghana Statistical Service; 2012 [Available from: http://www.statsghana.gov.gh/docfiles/2010phc/Census2010_Summary_ report_of_final_results.pdf.

11. Dobson JE, Bright EA, Coleman PR, Durfee RC, Worley BA. LandScan: a global population database for estimating populations at risk. Photogramm Eng Remote Sens. 2000;66(7):849-57.

12. Becher H, Muller O, Jahn A, Gbangou A, Kynast-Wolf G, Kouyate B. Risk factors of infant and child mortality in rural Burkina Faso. Bull World Health Organ. 2004;82(4):265-73.

13. Global Moran's I. How Spatial Autocorrelation (Global Moran's I) works [cited 2018 17/07/2018]. Available from: http://pro.arcgis.com/en/pro-app/tool-reference/ spatial-statistics/h-how-spatial-autocorrelation-moran-s-i-spatial-st.htm.

14. Gething PW, Johnson FA, Frempong-Ainguah F, Nyarko P, Baschieri A, Aboagye $P$, et al. Geographical access to care at birth in Ghana: a barrier to safe motherhood. BMC Public Health. 2012;12(1):991.

15. Dangisso MH, Datiko DG, Lindtjorn B. Accessibility to tuberculosis control services and tuberculosis programme performance in southern Ethiopia. Glob Health Action. 2015;8:29443.

16. United Nations Development Program Ghana. Improve maternal health MDG 52015 [Available from: http://www.gh.undp.org/content/ghana/en/ home/post-2015/mdgoverview/overview/mdg5.html.

17. Wiggins $S$, Marfo K, Anchirinah V. Protecting the forest or the people? Environmental policies and livelihoods in the forest margins of southern Ghana. World Dev. 2004;32(11):1939-55.

18. MacKinney A, Coburn A, Lundblad J, McBride T, Mueller K, Watson S. Access to rural health care-a literature review and new synthesis. Policy report Rupri: rural policy research institute; 2014.

19. Finnie RK, Khoza LB, van den Borne B, Mabunda T, Abotchie P, Mullen PD. Factors associated with patient and health care system delay in diagnosis and treatment for TB in sub-Saharan African countries with high burdens of TB and HIV. Tropical Med Int Health. 2011;16(4):394-411.

20. Ross JM, Cattamanchi A, Miller CR, Tatem AJ, Katamba A, Haguma P, et al. Investigating barriers to tuberculosis evaluation in Uganda using geographic information systems. Am J Trop Med Hyg. 2015;93(4):733-8.

21. Langford M, Higgs $G$. Measuring potential access to primary healthcare services: the influence of alternative spatial representations of population. Prof Geogr. 2006;58(3):294-306.

22. Kuupiel D, Bawontuo V, Mashamba-Thompson TP. Improving the accessibility and efficiency of point-of-care diagnostics Services in low-and Middle-Income Countries: lean and agile supply chain management. Diagnostics. 2017;7(4):58.

23. Bhaduri B, Bright E, Coleman P, Dobson J. LandScan. Geoinformatics. 2002:5(2):34-7.

24. World Health Organization. World Health Organization Model List of Essential In Vitro Diagnostics First edition (2018). Geneva: World Health Oraganization; 2018. p. 2018.

\section{Publisher's Note}

Springer Nature remains neutral with regard to jurisdictional claims in published maps and institutional affiliations.
Ready to submit your research? Choose BMC and benefit from:

- fast, convenient online submission

- thorough peer review by experienced researchers in your field

- rapid publication on acceptance

- support for research data, including large and complex data types

- gold Open Access which fosters wider collaboration and increased citations

- maximum visibility for your research: over $100 \mathrm{M}$ website views per year

At BMC, research is always in progress.

Learn more biomedcentral.com/submissions 